\title{
Calcium Ion Distribution in Nascent Pioneer Axons and Coupled Preaxonogenesis Neurons in situ
}

\author{
David Bentley, ' Peter B. Guthrie, ${ }^{2}$ and Stanley B. Kater ${ }^{2}$ \\ 'Department of Molecular and Cell Biology, University of California, Berkeley, California 94720 and ${ }^{2}$ Department of \\ Anatomy and Neurobiology, Colorado State University, Fort Collins, Colorado 80523
}

The "calcium hypothesis" of regulation of growth cone motility and neurite elongation has derived from analysis of a variety of neurons growing in vitro. It proposes that calcium ion concentration within growth cones is an important regulator of motility and growth. We now extend this analysis by investigating calcium concentrations within growth cones and nascent neurites of identified embryonic neurons growing on their normal substrate in situ.

The pair of Ti1 pioneer neurons are the first to extend axons in limb buds of grasshopper embryos. Their growth cones migrate along a stereotyped pathway, where they encounter a series of guidance cues, including preaxonogenesis afferent neurons (guidepost cells). By injecting a pioneer neuron with fura-2 dye, we measured calcium concentration in the injected neuron, and in cells to which it became dye-coupled, at successive stages of pioneer outgrowth through the limb.

Pioneer neurons undergoing axonogenesis had calcium concentrations in the above-100-nM range characteristic of a variety of neuron types studied in vitro. In pioneer neurons not yet in contact with guidepost cells, a shallow calcium concentration gradient, highest at the growth cone, was often observed. Guidepost cells that had not begun axonogenesis had lower calcium concentrations, in the $65 \mathrm{~nm}$ range. Therefore, an increase in cytosolic calcium concentration may be associated with the onset of axonogenesis. Nascent pioneer neurons were fura-2 dye-coupled to each other and established coupling with contacted guidepost cells. Calcium concentration measurements along pioneer neurites suggest that calcium ions also are transferred from pioneer neurons to these coupled guidepost cells. Thus, calcium concentration within nascent pioneer neurites appears to be altered by contact with specific in situ guidance substrates.

In growth cones studied in vitro, calcium ion concentration appears to be an important feature that integrates environmental input and, in turn, regulates behavior (Anglister et al., 1982; Bolsover and Spector, 1986; Connor, 1986; Mattson and Kater, 1987; Kater et al., 1988; Lipscombe et al., 1988; Forscher, 1989; Lankford and Letourneau, 1989; Silver et al., 1989, 1990; Streit

Received Sept. 10, 1990; revised Dec. 6, 1990; accepted Dec. 7, 1990.

We thank Robert $S$. Zucker and Karen Lankford for criticizing the manuscript. Support was provided by NIH Grants NS 09074 to D.B. and NS 24683 and NS 28332 to S.B.K. and P.B.G.

Correspondence should be addressed to David Bentley, Life Sciences Addition, Department of Molecular and Cell Biology, University of California, Berkeley, CA 94720.

Copyright (C) 1991 Society for Neuroscience $0270-6474 / 91 / 111300-09 \$ 03.00 / 0$ and Lux, 1989). In a variety of cell types, growth cone motility and neurite elongation have been correlated with intracellular calcium concentration (Anglister et al., 1982; Connor, 1986; Cohan et al., 1987; Goldberg, 1988; Lankford and Letourneau, 1989; Silver et al., 1989, 1990; Tolkovsky et al., 1990). Interactions with both soluble and substrate molecules influence intracellular calcium levels. Exposure of growth cones to a variety of neurotransmitters can arrest or otherwise regulate growth (Haydon et al., 1984; Connor et al., 1987; Mattson et al., 1988; McCobb and Kater, 1988; McCobb et al., 1988). This effect appears to be mediated, at least in part, by alteration of intracellular calcium levels through voltage-gated calcium channels (Cohan and Kater, 1986; Cohan et al., 1987; Kater et al., 1988). Binding of antibodies to the cell surface adhesion molecules Ll and N-CAM, or cell-cell adhesion, also can elevate intracellular calcium (Schuch et al., 1989). Extracellular matrix molecules and their receptors also appear to be linked to intracellular second-messenger systems (Bixby, 1989). In addition to the direct effect of binding ligands, adhesion may initiate secondary effects through stretch-activated or stretch-inactivated potassium ion channels in growth cones (Morris and Sigurdson, 1989; Sigurdson and Morris, 1989). Voltage changes generated by these ion fluxes are also thought likely to effect intracellular calcium levels.

Within the growth cone, calcium ion concentration changes could regulate motility and elongation through a variety of cellular processes (Forscher, 1989). The ability of agents such as phalloidin and taxol, which affect actin or tubulin polymerization, to block or reverse the effects of calcium ionophores suggests that a major route for calcium control of the growth cone is through regulation of the stability of cytoskeletal elements (Lankford and Letourneau, 1989).

This information, derived from cell lines and from regrowth of dissociated cells in culture, makes it desirable to examine the relationship between calcium concentration and growth cone behavior of embryonic neurons in situ. Among the most intensively studied growth cones in situ are those of insect embryos and imaginal disks. The accessibility and identifiability of these neurons facilitates lineage, genetic, and pathway analysis, and in addition, many extracellular matrix, matrix receptor, and cell adhesion molecules are now known to have both insect and vertebrate homologues (Anderson, 1988; Fessler and Fessler, 1989). Embryonic insect neurons and muscle cells also appear to have several conventional types of calcium channels (Wei and Salkoff, 1986; Byerly and Leung, 1988; Leung et al., 1989). We have here begun examination of one set of insect neurons, the afferent pioneer neurons in grasshopper embryonic limb buds. 
The pair of Til pioneer neurons are the first afferent neurons to initiate axonogenesis in the limb buds of grasshopper embryos (Bate, 1976; Keshishian, 1980) and establish a pathway (Fig. 1) essential for normal development of the PNS (Klose and Bentley, 1989). Their growth cones migrate along a highly stereotyped route to the CNS (Ho and Goodman, 1982; Keshishian and Bentley, 1983; Caudy and Bentley, 1986; Lefcort and Bentley, 1987). While their initial outgrowth may be oriented by internal cell polarity (Lefcort and Bentley, 1989), they are subsequently guided by a hierarchical series of extrinsic cues that includes a set of identified preaxonogenesis afferent neurons (guidepost neurons) and limb segment boundary cells, and possibly by an epithelial polarity cue. In some limb regions, growth cones normally interact extensively with the basal lamina (Anderson and Tucker, 1988; Condic and Bentley, 1989a), but the presence of basal lamina is not a requirement for migration along the normal route (Condic and Bentley, 1989c). The growth cones migrate under tension and rapidly establish adhesive contacts directly with the surfaces of boundary cells and guidepost cells (Condic and Bentley, 1989b). Guidance cues appear to be located by filopodial exploration (Bentley and Toroian-Raymond, 1986). Time-lapse video photography of growth cones migrating on the in situ substrate shows that, in some limb locations, steering is mediated by asymmetrical veil extension or by selective branch retraction (O'Connor et al., 1990). However, at other sites, a single filopodial contact with a high-affinity substrate is sufficient to reorient the growth cone (O'Connor et al., 1990). This phenomenon suggests that intracellular signaling mechanisms may be involved in growth cone steering. To begin an analysis of possible signaling mechanisms, we here investigate calcium ion distribution in pioneer neurons prior to and during axonogenesis.

Preliminary results have appeared previously in abstract form (Guthrie et al., 1989).

\section{Materials and Methods}

Schistocerca americana eggs at the 30-35\% stages of development (Caudy and Bentley, 1986) were obtained from a colony maintained at Berkeley. Embryos were removed from the eggs in saline (Lefcort and Bentley, 1987); the segments anterior to the third thoracic segment (T3; metathoracic) were removed, and the anterior surfaces of the T3 limb buds were lowered onto a strongly adhesive poly-L-lysine coated $(5 \mathrm{mg} / \mathrm{ml})$ glass coverslip. Adherent limbs were opened along the posterior aspect with a glass needle, the epithelium was unrolled onto the coverslip surface, and the interior mesodermal cells were removed with a suction pipette. With Nomarski optics on a Zeiss IM405 inverted microscope, the Til pioneer neurons could then be directly viewed on the interior (basal) surface of the epithelium. Preparations were maintained on the stage at $23 \pm 2^{\circ} \mathrm{C}$.

Neuron cell bodies were penetrated with thin-walled microelectrodes containing fura-2 (pentapotassium salt; $10 \mathrm{~mm}$ in $\mathrm{H}_{2} \mathrm{O}$; Molecular Probes, Eugene, OR). Fura-2 was injected with a 1-nA hyperpolarizing current ( $50 \%$ duty cycle) for $2-5 \mathrm{~min}$. Average intracellular concentrations estimated by comparison with calibrated glass microcapillary tubes filled with known concentrations of fura- 2 were as follows: Til cell bodies, $600 \mu \mathrm{M}(n=10)$; Til axons, $360 \mu \mathrm{M}(n=10)$; Til growth cones, 270 $\mu \mathrm{M}(n=4) ; \mathrm{Fe} 1$ cell bodies, $120 \mu \mathrm{M}(n=5)$; $\operatorname{Tr} 1$ cell bodies, $42 \mu \mathrm{M}(n$ $=4)$. These concentrations were sufficient for visualization of the cell bodies, axons, branches, and growth cones. While filopodia often could be observed, calcium ion concentrations in filopodia were not measured because of the high (cell-damaging) levels of illumination required. The fura- 2 was allowed to diffuse through the cells for a minimum of 15 min before observations were taken. For most cells, two to six images were taken over the course of the next hour. However, because these growth cones migrate slowly (about $5 \mathrm{hr}$ for each $1 \%$ of development at $30^{\circ} \mathrm{C}$ ), we did not follow the migration of individual growth cones

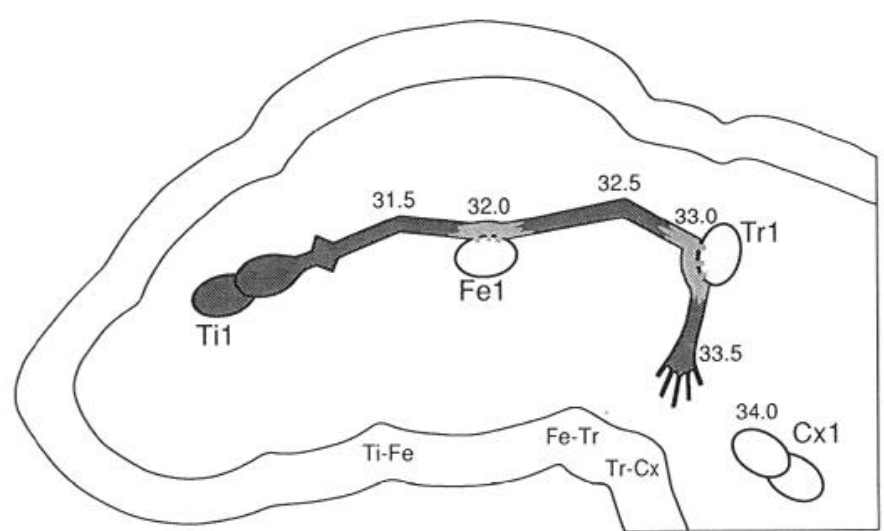

Figure 1. A schematic diagram of outgrowth of the Til pioneer axons through a $31-34 \%$-stage limb bud. The sibling Til cell bodies lie in the tibia, and their growth cones migrate proximally across several prospective limb segment boundaries to reach the CNS. Typical locations of the growth cones at successive developmental stages are indicated by the corresponding numbers $(31.5-34.0)$. Along their route, the growth cones orient toward, contact, and become dye-coupled to a series of preaxonogenesis (guidepost) neurons ( $\mathrm{Fel}, \mathrm{Tr} 1, \mathrm{Cxl}$ pair). Cytosolic calcium ion concentration (indicated by shading density) is higher in the pioneer neurons than in the preaxonogenesis neurons. $\mathrm{Ti}-\mathrm{Fe}$, tibiafemur boundary; $\mathrm{Fe}$ - $\mathrm{Tr}$, femur-trochanter boundary; $\mathrm{Tr}$ - $\mathrm{CX}$, trochanter-coxa boundary. Dorsal, up; proximal, to the right.

over a significant portion of their pathway. Rather, these readings should be regarded as "snapshots" taken at specific developmental stages.

Dye coupling to other cells and calcium ion concentrations were determined from the fluorescence of the fura-2. Efficient passage of the UV excitation light was obtained using a quartz collector on an $\mathrm{HBO}$ 50 -W mercury lamp and a $40 \times$ NA-1.3 oil Nikon Fluorite objective. The excitation light was directed through a computer-controlled shutter/ filter wheel system for the two fura- 2 excitation wavelengths ( $350 \pm 10$ $\mathrm{nm}$ and $380 \pm 10 \mathrm{~nm}$ ). Neutral-density filters were inserted in the excitation path as necessary to reduce bleaching and saturation of fluorescence. The image was directed to an intensified CCD camera (Quantex Corp., Sunnyvale, CA), and the output of the camera was analyzed by a Quantex QX7 Image/Acquisition/Analysis System. Calcium concentrations were estimated from the ratio of emission intensities (495$\mathrm{nm}$ long-pass filter) at two excitation wavelengths, according to the equation $\left[\mathrm{Ca}^{2+}\right]=K_{D} *\left[\left(R-R_{\min }\right) /\left(R_{\max }-R\right)\right] * F_{O} / F_{S}$ (see Grynkiewicz et al., 1985). For this system, $K_{D}=224, R_{\min }=0.48, R_{\max }=13.25$, and $F_{O} / F_{S}=10$. For all images, a mask was created from the raw fluorescent image to restrict analysis to the cell bodies and processes of the pioneers and guidepost cells.

Because we were interested in obtaining calcium ion concentrations from regions of the cells that varied considerably in thickness, a concern was the relationship between optical path length and computed calcium ion concentration in this system. To calibrate this relationship, a tapering microelectrode was filled with a solution of $90 \mu \mathrm{M}$ fura-2. The microelectrode was then placed on the microscope stage, and using an optical micrometer, readings were taken at positions where the microelectrode ranged from 31 to $2.5 \mu \mathrm{m}$ in diameter. A $4.6 \%$ decrease in the ratios of fluorescence emissions used to calculate calcium concentration was recorded over the $92 \%$ decrease in optical path length (from 31 to $2.5 \mu \mathrm{m}$ ). Note that the shorter optical path length resulted in a slightly lower computed calcium concentration. This calibration indicates that the computed calcium concentration was relatively uneffected by optical path length within the range appropriate here, and that the shorter optical path length at the growth cone would not bias the computed calcium concentration to a higher level relative to the cell body.

For photoinactivation experiments, a $20-\mu$ m-diameter circular illumination spot was focused on the target, with a $380-\mathrm{nm}$ excitation filter and a neutral-density filter in the pathway. The filter wheel was then rotated to an open slot, and unfiltered UV light was delivered to the target for $60 \mathrm{sec}$.

At the completion of in situ observations, embryos were fixed overnight in $4 \%$ formaldehyde in saline and labeled with serum antibodies against horseradish peroxidase with the protocol of Caudy and Bentley 

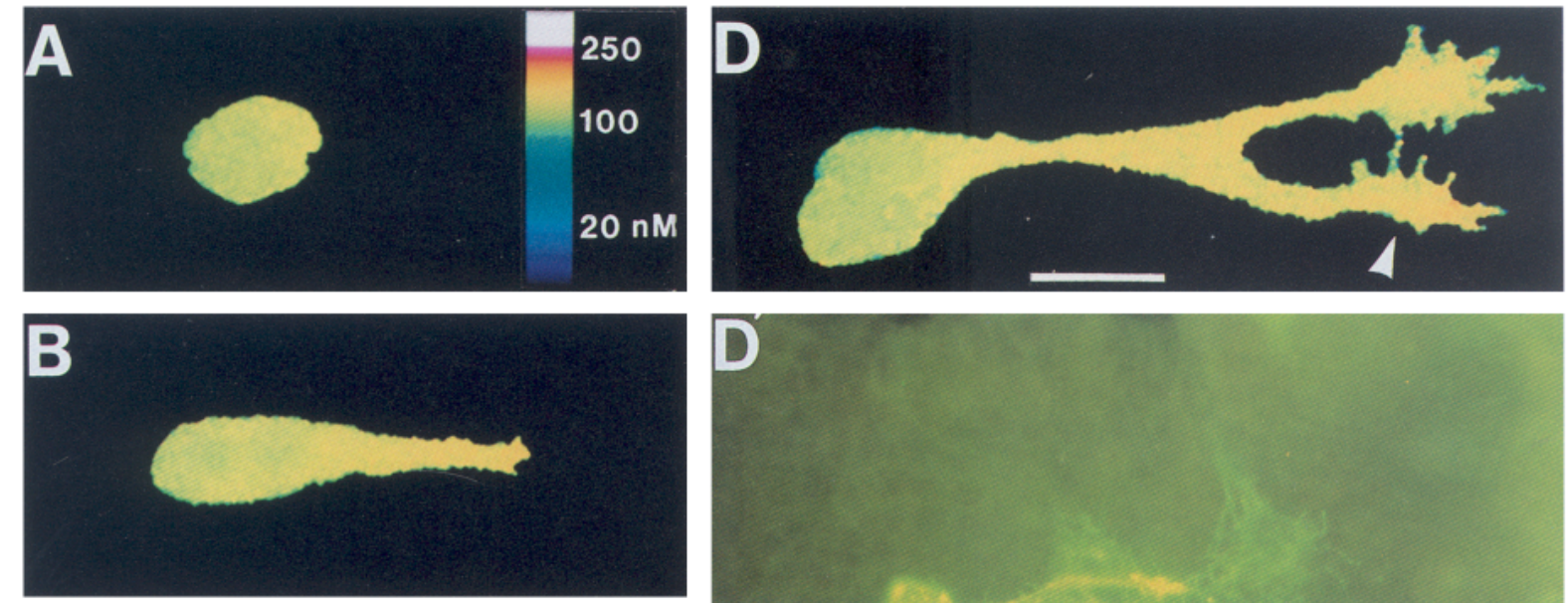

C
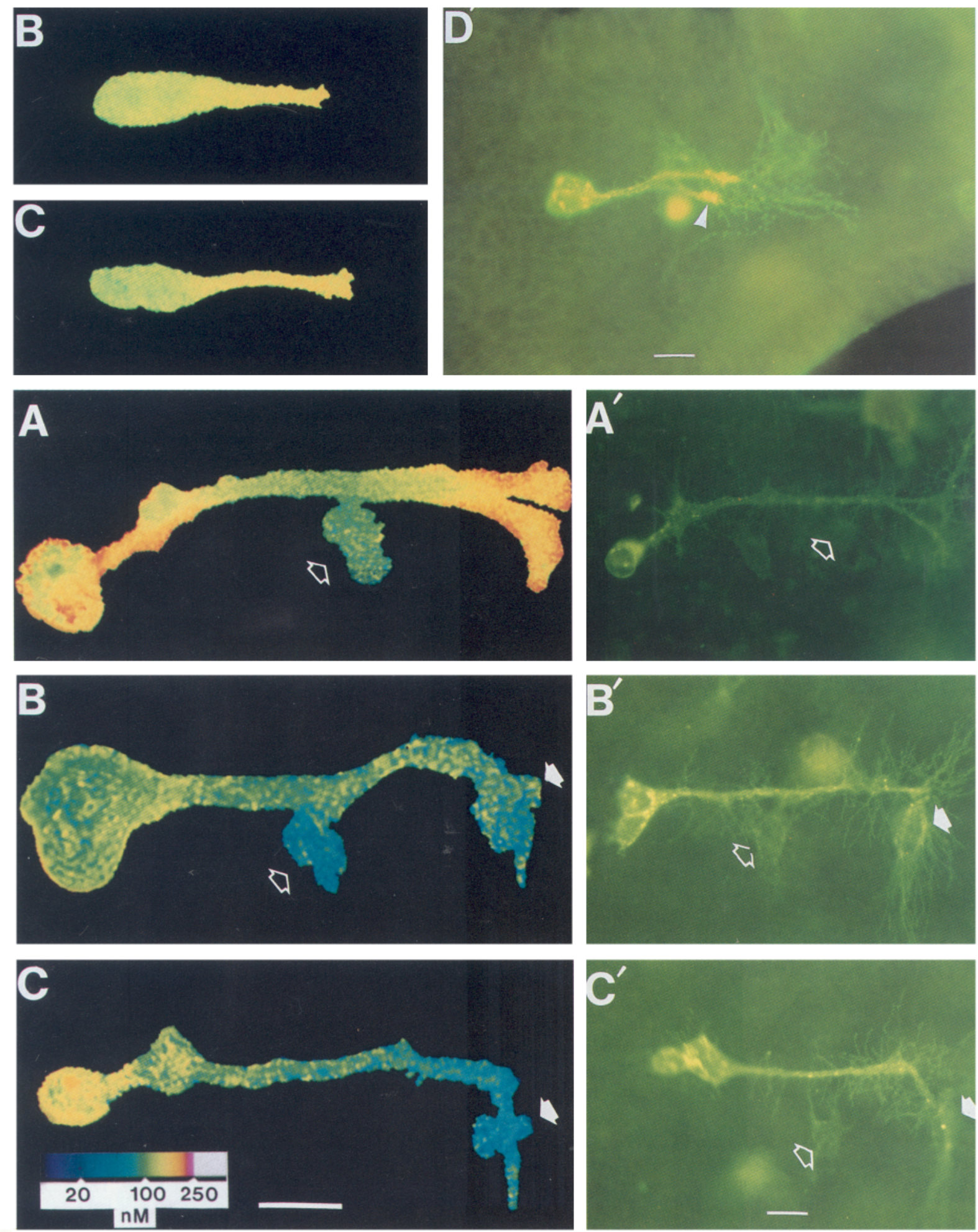
(1986). These antibodies selectively label insect neurons (Jan and Jan, 1982; Snow et al., 1987) and show the positions of pioneer growth cone filopodia, as well as other nascent neurons. Staging of growth cone location along the pathway was based upon these images (cf. Figs. 2, 3; see also Caudy and Bentley, 1986).

The results are based upon examination of 62 Til neurons ( 31 pairs), 20 preaxonogenesis Fel (guidepost) neurons, and 12 preaxonogenesis Trl (guidepost) neurons in 31 embryos at the following stages: $30.5-$ $31.5 \%, n=6 ; 32.0-32.5 \%, n=5 ; 33.0-33.5 \%, n=9 ; 34.0-34.5 \%, n=$ 11.

\section{Results}

\section{Calcium ion concentration in cell bodies of pioneer neurons}

To estimate calcium ion concentration in cell bodies of pioneer neurons, we selected a subset of cells that satisfied a set of criteria designed to minimize possible effects of the dissection or impalement of cells. First, at all stages of development examined, the pair of pioneer neurons is strongly dye-coupled (Keshishian, 1980). Consequently, within a few minutes of filling of one pioneer, the sibling cell also became filled with fura-2 (Fig. 2). When the initially filled cell was damaged by the microelectrode penetration, its calcium ion concentration was much higher than that of its sibling. Because calcium might flow from the damaged to the undamaged cell, we eliminated all cell pairs whose calcium ion concentrations differed by more than $15 \%$. Second, we eliminated all cell pairs that had along their axons a "hotspot" of more than $150 \%$ of the average calcium concentration in the rest of the cell, because such cells might have been stretched or nicked during the dissection. Third, we eliminated possibly unhealthy cell pairs whose average calcium ion concentration was more than $150 \%$ of that of the pairs remaining after the first two criteria had been satisfied. This left a set of 18 pioneer neurons (nine pairs) in nine embryos roughly equally distributed in age from $30.5 \%$ to $34.0 \%$. The average calcium ion concentration in cell bodies of this set was $102.3 \pm 1.3 \mathrm{nM}( \pm$ SEM). With less stringent elimination criteria allowing double the average calcium concentration, we observed 48 cells ( 24 pairs) with an average concentration of $113 \pm 6.3 \mathrm{~nm}$.

\section{Distribution of calcium ion concentration along nascent pioneer neurons}

To evaluate the possibility of a graded distribution of calcium ions along growing pioneer neurons, we compared calcium ion concentrations at the cell body and at the growth cone, using

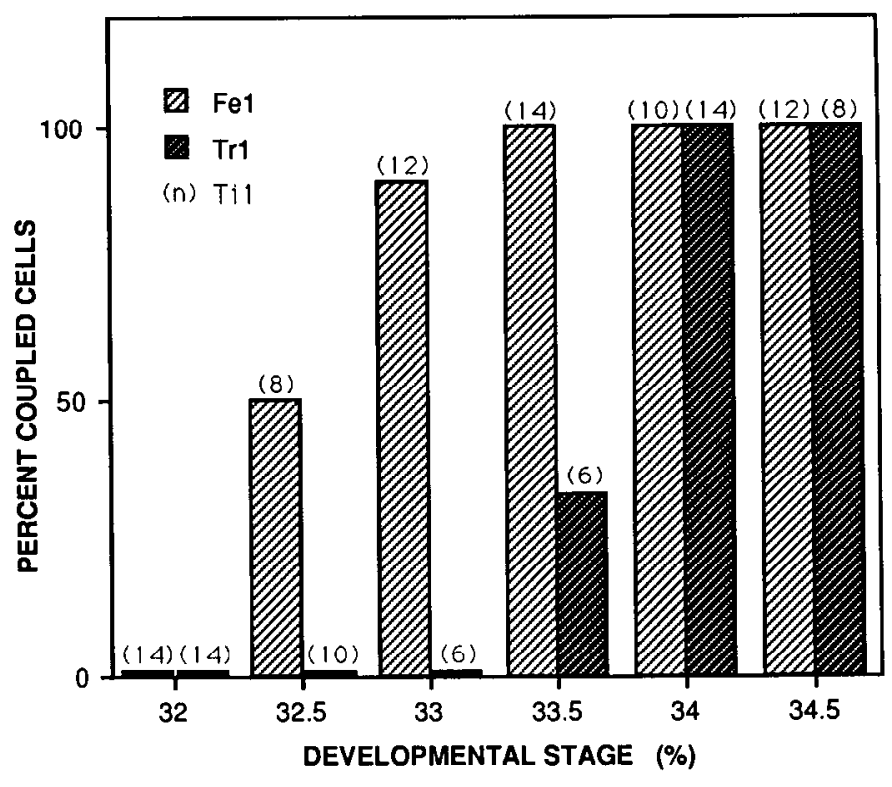

Figure 4. Time course of the establishment of fura-2 coupling between the Til pioneer axons and the Fel and Trl guidepost cells. Pioneer neurons were filled with fura-2 by intracellular injection, and guidepost cells were subsequently observed for coupling (numbers of filled Til neurons at each stage shown at top of columns).

the set of optimal-condition neurons defined above. From these, cell pairs were eliminated that did not have growth cones at least a cell-body diameter in length or that had become dyecoupled to the $\mathrm{Fe} 1$ or $\mathrm{Tr} 1$ preaxonogenesis neurons. This left a set of 12 pioneer neurons (six pairs). In this set, the average calcium ion concentration was $101.8 \pm 1.3 \mathrm{nM}$ in the cell bodies and $118.1 \pm 6.8 \mathrm{nM}$ in the growth cones. Thus, the calcium ion concentration was higher in the growth cones by an average of about $16 \mathrm{~nm}$. It seems possible, therefore, that growing pioneer neurons sometimes have a shallow gradient with a higher calcium ion concentration at the growth cone (Fig. $2 B-D$ ).

\section{Calcium ion concentration in preaxonogenesis afferent neurons}

Migrating pioneer neuron growth cones encounter and dye-couple to two preaxonogenesis guidepost neurons, Fel and $\operatorname{Tr} 1$,

\footnotetext{
Figure 2. Cytosolic calcium ion concentrations in Til pioneer neurons during early axonogenesis, before coupling is established with guidepost neurons. One cell of each pair has been intracellularly injected with fura-2; as the cell pair is strongly dye-coupled, the sibling has passively filled with fura- 2 by diffusion. Fura- 2 concentrations are similar in both cells. In $A-D$, color represents calcium ion concentration, as indicated on the color scale in $A$. Cells are typically in the 100-115-nM range. Along the length of the cell, a shallow calcium ion concentration is often seen, with the growth cones being at a slightly higher level. $A, 30.5 \%$ stage (onset of axonogenesis); $B, 31.5 \% ; C, 31.5 \%, D, 32.5 \%$. In $D$, the two growth cones have separated (arrowhead, ventral growth cone). After the fura-2 measurements, limb were fixed and labeled with neuron-selective (anti-HRP) antibodies to reveal the disposition of filopodia and placement of guidepost neurons. $D^{\prime}$ shows the antibody labeling of $D$ (arrowhead, ventral growth cone). Dorsal, up; proximal, to the right. Scale bars: $D, 25 \mu \mathrm{m}$ for $A-D ; D^{\prime}, 30 \mu \mathrm{m}$.

Figure 3. Cytosolic calcium ion concentrations in the Til pioneer neurons, and in the Fel and Trl guidepost neurons after the establishment of dye coupling. $A-C$, One cell of each pioneer pair was intracellularly injected with fura- 2 dye. The sibling Til neuron and coupled guidepost cells were then passively filled with fura-2 by diffusion. Cytosolic calcium ion concentrations are represented by color, as shown on the color scale in $C$. $A^{\prime}-C^{\prime}$, Neuron-selective (anti-HRP) antibody labeling of the cells in $A-C$, showing the disposition of pioneer growth cone filopodia and the placement of guidepost cells. $A$ and $A^{\prime}$, A $33 \%$-stage pioneer pair; though the pioneer growth cones are extending dorsally and ventrally along the $\operatorname{Tr}-\mathrm{Cx}$ segment boundary (see Fig. 1) and are in contact with the $\operatorname{Trl}$ guidepost cell, fura-2 dye coupling is not yet established. The pioneers are coupled to $\mathrm{Fel}$ (arrow). Cytosolic calcium levels are higher in the pioneers than in cell $\mathrm{Fel}$; within the pioneers, the lowest calcium levels are in the vicinity of Fel. $B$ and $B^{\prime}$, Pioneer neurons at a slightly later stage than in $A$ are coupled to both cell Fel (open arrows, $B$ and $\left.B^{\prime}\right)$ and cell $\mathrm{Tr} 1$ (solid arrows, $B$ and $B^{\prime}$ ). Both guidepost cells have lower cytosolic calcium levels than the pioneers. $C$ and $C^{\prime}, \mathrm{A} 33.5 \%$ pioneer pair is extending growth cones ventrally along the $\mathrm{Tr}-\mathrm{Cx}$ boundary (stage shown in Fig. 1). Cell Fe1 (open arrow, $C$ ) is unusually displaced from the Til axons and is not coupled to them. Cell $\operatorname{Tr} 1$ (solid arrows, $C$ and $C$ ) is coupled to the pioneers and has a lower cytosolic calcium level. Dorsal, up; proximal, to the right. Scale bars: $C, 25 \mu \mathrm{m}$ for $A-C ; 20 \mu \mathrm{m}$ for $A^{\prime}-C^{\prime}$.
} 

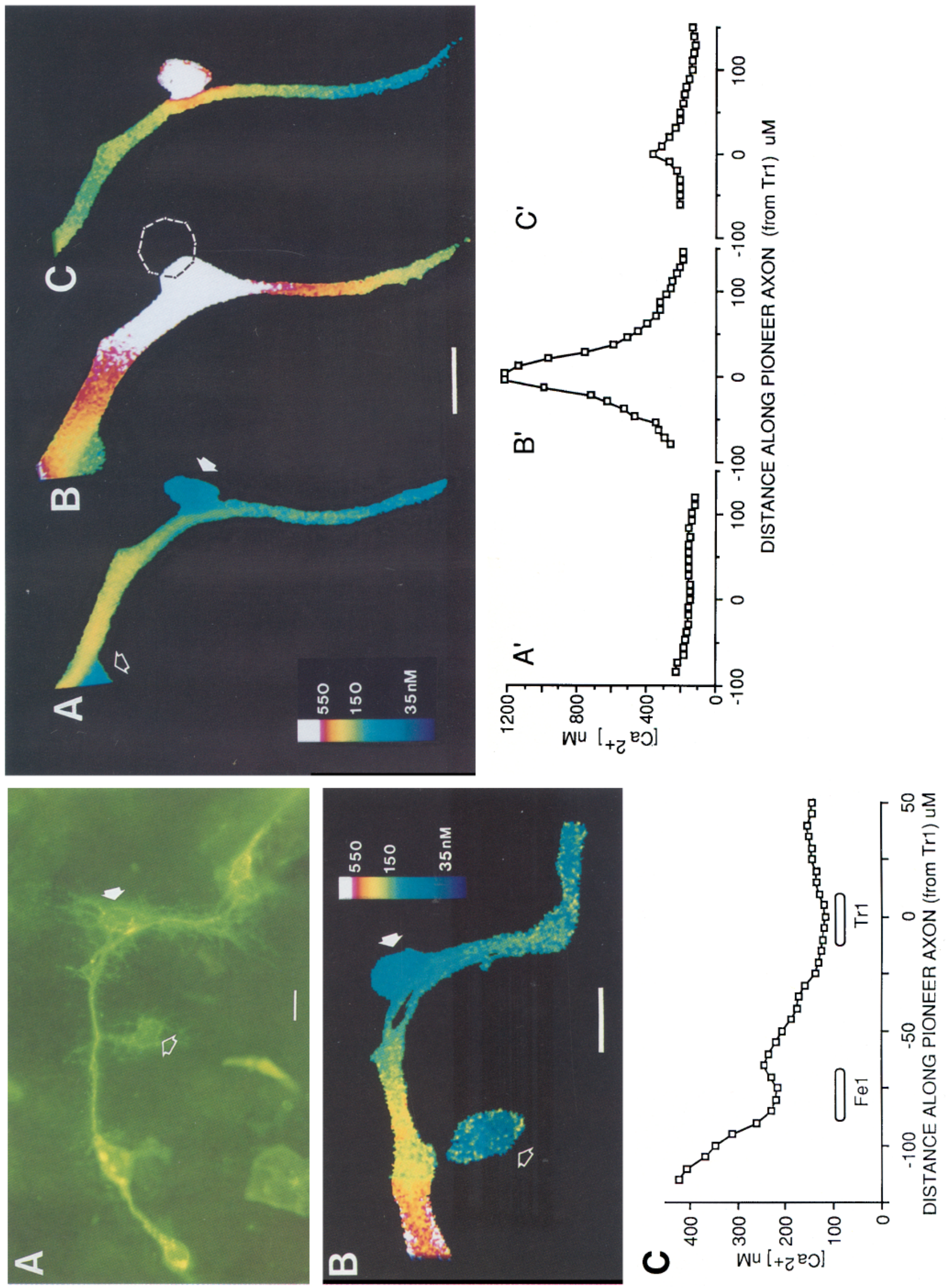
along their pathway in the distal limb. In limbs of the appropriate stages, fura- 2 passes into these preaxonogenesis neurons within a few minutes of reaching them (Figs. 3, 4, 5B, 6A). Following this initial filling, the fura- 2 concentration appears to remain stable in these cells for relatively long periods ( $>1 \mathrm{hr}$ ). Consequently, this indirect filling makes it possible to assess calcium ion concentration in these cells (but only after dye coupling with the pioneer neurons has been established). Cells were considered for this set that had stable levels of fura-2 at an estimated concentration of $30 \mathrm{~nm}$ or above (see Materials and Methods). Most cells in this group had similar calcium concentrations (see below); a few cells were eliminated that had calcium concentrations more than double this level and thus appeared damaged. The seven Fel neurons satisfying these criteria had an average calcium ion concentration of $65.9 \pm 4.5 \mathrm{nM}$. Six $\operatorname{Tr} 1$ neurons satisfying these criteria had an average calcium ion concentration of $66.8 \pm 4.2 \mathrm{nM}$. The Til, Fel, and $\mathrm{Tr} 1$ cells are all afferent neurons. While the Til neurons initiate axonogenesis at the $30.5 \%$ stage, $\mathrm{Fel}$ and $\mathrm{Tr} 1$ axonogenesis is delayed until after the $35 \%$ stage. At the stages when we assayed them, the Fel and $\operatorname{Tr} 1$ neurons are several hours preaxonogenesis, whereas the Til neurons are initiating or undergoing axonogenesis. The average calcium ion concentration of both preaxonogenesis (Fel, Trl) neurons was about $66 \mathrm{nM}$, whereas that of the Til neurons, undergoing axonogenesis, was above 100 nM.

\section{The timing of fura-2 coupling between pioneer neurons and preaxonogenesis neurons}

We wished to determine how soon after pioneer growth cones encountered guidepost neurons fura- 2 coupling became established. As mentioned above, we did not monitor the process of establishment of coupling in the time frame of our observations. Rather, coupling was observed as an all-or-nothing situation: either fura-2 was transferred to the coupled cells within about $10 \mathrm{~min}$, or it did not transfer in the observation period. (There was a single exception where initially uncoupled Fe1 and Trl cells both became coupled within $20 \mathrm{~min}$; it seems likely that this was due to the restoration of coupling lost due to some aspect of the dissection or injection.) We tested coupling between the pioneers and cell Fel in 31 embryos at various stages of development (Fig. 4). No coupling was observed in limbs at the $32.0 \%$ stage or earlier, but by the $33.0 \%$ stage or later, all Fel cells were coupled to the pioneers (with the exception of a single limb with an ectopic Fe1). These data suggest that the Fel cells usually become fura-2-coupled to the pioneers at about the $32.5 \%$ stage.

We also tested coupling between the $\operatorname{Tr} 1$ cell and the pioneers in the same set of 31 embryos (Fig. 4). No coupling was observed at the $33.0 \%$ stage or at earlier stages, but all cells were coupled by the $34.0 \%$ stage. This suggests that fura- 2 coupling occurs between these cells at about the $33.5 \%$ stage. Thus, for both the Fel cell and the $\operatorname{Tr} 1$ cell, the lag between arrival of the pioneer growth cones at the cell and the establishment of coupling that would allow passage of fura- 2 observable with our system was about $0.5 \%$ of development.

As has been reported using other dyes (Keshishian, 1980), epithelial cells were strongly intercoupled, and mesodermal cells were also strongly intercoupled when tested with fura- 2 . However, we observed no dye coupling at the stages tested between pioneer neurons and epithelial segment boundary cells at the tibia-femur, femur-trochanter, or trochanter-coxa boundaries.

\section{Calcium ion transfer between pioneer neurons and guidepost cells}

Because the nascent pioneer axons appear to have a higher internal calcium ion concentration than the guidepost neurons, and because these cells become dye coupled, calcium ions might diffuse down their concentration gradient from the pioneer neurites into the guidepost neurons. Several observations suggest that this is the case. First, pioneer growth cones that are at stages close to, but preceding, coupling to Fel or Tr1 (Figs. 2D, 3A) often had a higher calcium ion concentration than growth cones of later-stage neurons that had established coupling (Fig. 3B,C). This pattern is consistent with the possibility that coupling of a nascent axon to a guidepost cell can lower calcium ion concentration within a nearby growth cone.

Calcium ions might also pass locally from pioneer axons to guidepost cells in the region where they are coupled. We examined 12 instances where pioneer axons crossed a guidepost cell that was coupled and that was at a substantially (>30 nM) lower calcium ion concentration than the average concentration

Figure 5. Guidepost cells appear to act as calcium sinks for coupled pioneer axons. Although pioneer axons often have lower apparent calcium levels where they cross over, or pass close to, guidepost cells, optical estimation of calcium concentration in these cases of close adjacency is subject to possible summation and light-scatter errors. Such errors can be discounted if the pioneer axons pass at a distance from the coupled guidepost cell. $A$, Immunofluorescent labeling shows a preparation where guidepost cell Fel (open arrow) is displaced more than a cell diameter from the pioncer axons, with fine processes extending between the axons and Fel. $B$, Intracellular injection of fura- 2 into one pioneer neuron cell body reveals that Fel (open arrow) is nevertheless dye-coupled to the pioneers. Calcium ion concentrations are represented by color, as shown on color scale in $B$. Solid arrows, cell Tr1. Dorsal, up; proximal, to the right. Scale bars: $A, 20 \mu \mathrm{m} ; B, 25 \mu \mathrm{m}$. $C$, Although in this preparation the calcium levels in the pioneer cell bodies were elevated by the microelectrode penetration, measurement of cytosolic calcium levels along the pioneer axons nonetheless reveals a reduction in calcium concentration in the vicinity of cell Fel. Therefore, the measured decreases in calcium values within the pioneer axons near coupled guidepost cells appear to reflect a true reduction in calcium, rather than spatial summing errors. The open ovals indicate the positions and calcium concentrations of the Fel and Trl guidepost cells.

Figure 6. Effect of irradiation uncoupling of a guidepost cell. A, An intracellularly injected 33.5\%-stage Til pioneer neuron is fura-2 coupled to both cell Fel (open arrow) and cell Trl (solid arrow). Both guidepost cells have a lower cytosolic calcium concentration than the pioneer axons. Within the pioneer axons, the calcium level is slightly depressed in the vicinity of cell $\operatorname{Tr} 1$. $B$, Six minutes after irradiating the perimeter of cell Tr1 with a 20- $\mu \mathrm{m}$-diameter circular UV beam (broken line), cytosolic calcium levels in both cell $\operatorname{Trl}$ and in the pioneer axon have risen above $1000 \mathrm{~nm}\left(\right.$ see $\left.B^{\prime}\right) . C$, Twenty minutes after the irradiation, cell $\operatorname{Tr} 1$ has died and become uncoupled from the pioneer axon. In the pioneer axon, cytosolic calcium concentration has returned toward normal levels, but is higher in the vicinity of cell $\operatorname{Tr} 1$ than it was when the pioneer was coupled to $\operatorname{Tr} 1 . A^{\prime}-C^{\prime}$ show calcium ion concentrations along the Til axons in $A, B$, and $C$, respectively. Calcium ion concentrations are represented by color, as shown on color scale in $A$. Dorsal, up; proximal, to the right. Scale bar, $25 \mu \mathrm{m}$ for $A-C$. 
throughout the pioneer neuron. In 11 of these cases, the calcium concentration in the axon was lower where it crossed the guidepost cell than elsewhere in the axon (Fig. $3 A, B$ ). Because of the possibility of optical cross talk between the pioneer axons and the guidepost cell bodies (the fura- 2 fluorescence from axons directly above the guidepost cell algebraically summing with the fluorescence within the guidepost cell itself), the most reliable measurements were taken from axons that did not pass directly over guidepost cells; in these cases, calcium concentration also was lower in the portion of the axons in closest proximity to the guidepost cells. In one preparation (Fig. 5), cell Fel was displaced more than a cell diameter away from the pioneer axons (though connectcd by finc processes), but calcium ion concentration was still lower in the axon region close to Fel. A similar situation was seen in the vicinity of cell $\operatorname{Tr} 1$, where the two pioneer axons separated slightly before reaching $\operatorname{Tr} 1$ (Fig. 5). Therefore, calcium ion concentrations do appear to be lower in the regions of pioneer axons that are close to coupled guidepost cells.

If coupling to guidepost cells locally lowers calcium concentration within pioneer neurons, then uncoupling of the cells ought to block this effect. To test this possibility, we killed coupled guidepost cells by focal UV irradiation in five limbs. A UV beam, approximately $20 \mu \mathrm{m}$ in diameter, was positioned to overlap the guidepost cell by about one third of its diameter at the cell site farthest from the pioneer axons, and the cell was irradiated for $60 \mathrm{sec}$ (Fig. 6). In each of these cases, the guidepost cell was initially strongly coupled to the pioneer neurons, and calcium ion concentration was substantially lower $(>30 \mathrm{~nm})$ in the guidepost cell than in the pioneer neuron. Following irradiation, the outcome in each case was the same: the guidepost cell changed to a high calcium ion level (and usually subsequently died). The pioneer neurons exhibited a transient increase in calcium ion concentration, but then returned toward normal levels, with calcium ion concentration in the vicinity of the guidepost cell no longer at a lower concentration than in the remainder of the axon. This is the expected outcome if coupling to the guidepost cell had been contributing to the locally decreased calcium ion level within the pioneer axons.

\section{Discussion}

While cytosolic calcium concentration in growth cones of cell lines and primary cultures of dissociated neurons has been extensively documented, little information is available for neurons in situ. We report here the levels and spatial distribution of free calcium ions in pioneer neurons undergoing axonogenesis on their in situ substrate. These concentrations are higher than those of other afferent neurons that are in the preaxonogenesis stage of differentiation. We also report that free calcium concentration is reduced in nascent neurites, and probably in growth cones, after the growth cones encounter the high-affinity guidance substrates provided by preaxonogenesis neurons. These results are also among the first data on calcium concentrations in insect growth cones.

\section{Calcium ion concentration in embryonic neurons}

In the set of 18 pioneer neurons most stringently selected to exclude injured cells, the calcium concentration in cell bodies averaged about $100 \mathrm{nM}$. With more relaxed criteria, including a set of 48 neurons, calcium concentration was about $115 \mathrm{nM}$. By filling cells with intracellular injection rather than fura-2 AM loading, ambiguities resulting from preferential association of the dye with intracellular organelles are avoided (Almers and Neher, 1985). Moreover, data were used only from cell pairs with similar calcium levels. Consequently, one cell of each pair was filled neither by transmembrane methods nor by injection, but through gap junctions. The data from these cells should be free of both preferential dye association and cell damage errors.

The 100-115 nM free calcium concentration observed in these insect pioneer neurons is comparable to levels recorded from many cell types. Reports include rat diencephalic neuron cell bodies (60-80 nM) and growth cones (up to $200 \mathrm{~nm}$; Connor, 1986), snail neuron growth cones (about $130 \mathrm{~nm}$; Cohan et al., 1987), frog sympathetic neuron cell bodies ( $80 \mathrm{nM}$ ) and growth cones (130 nM; Lipscombe et al., 1988), mouse N1E-1 15 neuroblastoma cell motile and advancing growth cones (60 nM; Silver et al., 1989), chick dorsal root ganglion cell growth cones (200-800 nM; Lankford and Letourneau, 1989), Xenopus spinal neuron cell bodies (60-80 nM) and growth cones (70-200 nM; Sun and Poo, 1987), and rat hippocampal neuron cell bodies (100 nM; Mattson et al., 1988).

We also recorded calcium concentrations in the cell bodies of 2 other identified embryonic afferent neurons, Fel and $\operatorname{Tr} 1$, that were in earlier stages of differentiation and that would initiate axonogenesis after the pioneers. The values in both these cell types were in close agreement in the 65-nM range and were thus lower than those in the Til afferent neurons, which were undergoing axonogenesis. This dissimilarity could be because of an intrinsic difference in the calcium levels of these neurons, or it could be associated with their preaxonogenesis state. The latter explanation seems more likely because the later behavior of the growth cones of these cells is very similar to that of the pioneer growth cones (Keshishian and Bentley, 1983). While this is the only information of which we are aware on calcium levels in embryonic neurons in situ before the initiation of axonogenesis, there are several comparisons of calcium levels in growing and nongrowing neurons and cell lines in vitro. In rat embryonic diencephalic neurons (Connor, 1986) and in identified neurons of the snail Helisoma, calcium levels were higher in growing than in nongrowing cells. Mouse N1E-1 15 neuroblastoma cells had growth cones that were motile and advanced at relatively low calcium levels (60 $\pm 5 \mathrm{~nm}$; Silver et al., 1989). These calcium concentrations were only slightly higher than concentrations in quiescent growth cones $(55 \pm 7 \mathrm{nM})$. Because we did not alter calcium concentration in pioneer growth cones or make time-lapse observations of the (calcium-lowering) effect of coupling to guidepost cells, we have no comparable data on the consequences of low calcium concentration for pioneer growth cone motility or elongation rate.

In some pioneer neurons, we observed a shallow gradient of calcium ion concentration, highest at the growth cone and lowest at the cell body. Other neurons did not have a gradient. Whether this feature might distinguish growing and nongrowing neurons was not determined. Using fura-2, gradients have been observed in rat diencephalic neurons (Connor, 1986) and Helisoma neurons (Cohan et al., 1987). In N1E-115 cells, extracellular recordings suggested that more voltage-activated calcium channels were present on the growth cone than in neurites (Anglister et al., 1982; see also Bolsover and Spector, 1986). Patch clamping revealed higher channel densities on growth cones than on neurites of PC12 cells (Streit and Lux, 1989), but not on slowly growing frog sympathetic neurons (Lipscombe et al., 1988). What role these gradients might play in outgrowth is not clear, and it 
may be that they are an epiphenomenon of mechanisms for controlling calcium level within the growth cone.

Ion manipulation and patch-clamp analyses of processes of embryonic insect (Drosophila) neurons and muscle cells in vitro have demonstrated a set of voltage-sensitive channels that are, in general, similar to those found on molluscan neurons (Wei and Salkoff, 1986; Byerly and Leung, 1988; Leung et al., 1989). This set includes calcium channels, found in relatively high density, which appear to include L-type (Pauron et al., 1987) and possibly other types of calcium channels. Growth cones of some molluscan neurons have stretch-activated and also stretchinactivated potassium-selective ion channels, and the current fluxes through these channels may affect voltage-sensitive calcium channels (Morris and Sigurdson, 1989; Sigurdson and Morris, 1989). The Til pioneer neurites maintain a substantial level of tension that effects rapid shortening of the neurite if either the cell body or the growth cone unadheres from the substrate (Condic and Bentley, 1989a). Because the pioneer growth cones evidently adhere directly to the plasma membrane of the preaxonogenesis neurons (Condic and Bentley, 1989b), tension-mediated calcium influxes, if present, might play a role in their behavior.

\section{Coupling between growing pioneer neurons and preaxonogenesis neurons}

Development of cells in the limb bud includes a set of spatially and temporally selective dye-coupling events. Mesodermal cells in the limb are extensively intercoupled, as are epithelial cells (Keshishian, 1980). The pioneer mother cell within the epithelium is initially dye-coupled to other epithelial cells, but it loses that coupling as it undergoes division and emerges from the epithelium. The sibling pioneer neurons remain coupled to each other, at least until their growth cones enter the CNS and also become coupled to all of the preaxonogenesis afferent neurons they encounter en route. Motor neuron growth cones emerging from the CNS do not, in general, become coupled to afferent neurons. However, one identified motor growth cone leaves the motor bundle with which it exits the CNS and fasciculates with the pioneer axons to cross from the ventral to the dorsal side of the limb; during this excursion, it becomes dye-coupled to the pioneer axons (Myers et al., 1990).

Using a monoclonal antibody against Lucifer yellow, Taghert et al. (1982) reported that some grasshopper central growth cones establish selective coupling through filopodia, and this also is possible between Ti1 pioneer growth cone filopodia and preaxonogenesis afferent neurons. With fura-2, we did not generally observe significant coupling between Til growth cones and preaxonogenesis neuron $\mathrm{Fe} 1$ until the $32.5 \%$ stage, and with neuron $\operatorname{Tr} 1$, until the $33.5 \%$ stage. In both these cases, therefore, the growth cones were past the preaxonogenesis neurons before this coupling was observed. This discrepancy may not be significant because it may well be that, with our less sensitive method, more extensive dye coupling must be established before dye transfer is detectable. Thus, substantial coupling definitely is present soon after the growth cone passes the cell, and it may occur earlier.

This dye coupling is likely to be mediated by gap junctions, which have been extensively characterized in insects (Bennett, 1978; Spray and Bennett, 1985; Ryerse, 1989). These arthropodtype channels, which are slightly larger than those of vertebrate gap junctions, are about $14 \AA$ in diameter and transfer negatively charged and neutral particles up to at least $1000 \mathrm{MW}$. Accep- tance characteristics for positively charged particles have been less well characterized, but at least some divalent cations pass through the channels. Thus, once coupling is established, transfer of calcium ions from the pioneer neurons, with a higher internal calcium ion concentration, to the preaxonogenesis neurons with the lower calcium ion concentration, should occur, as it does in other cell types (Saez et al., 1989). With fura-2 imaging, we observed that calcium ion concentration appears reduced within pioneer neurites in the vicinity of coupled preaxonogenesis neurons. If a coupled preaxonogenesis neuron is killed with a UV microbeam, then the local reduction in calcium concentration within the pioneer neurite is no longer observed. Although the possibility that some of this effect may be due to irradiation of pioneer neuron filopodia has not been excluded, it seems likely that calcium ions do flow through gap junctions of these coupled cells.

Transfer of calcium ions through gap junctions has been shown to be an important intercellular signaling mechanism between some coupled cells (Dunlap et al., 1987; Brehm et al., 1989). The calcium current considered here would be expected to elevate calcium concentration within the preaxonogenesis neurons and to reduce calcium concentration in the pioneer growth cones and neurites. What role, if any, this interaction might play has not been determined. The $\mathrm{Fe} 1$ and $\operatorname{Tr} 1$ preaxonogenesis neurons have been shown to remain capable of axonogenesis and pathfinding even if contact with pioneer growth cones is prevented (Keshishian and Bentley, 1983; Klose and Bentley, 1989). Whether the hypothesized reduction in calcium concentration within the pioneer growth cone or nascent neurite contributes to the high affinity for the preaxonogenesis neuron substrate remains to be tested. The results reported here do suggest, however, that the calcium ion concentration within pioneer growth cones and neurites extending on their in situ substrate is selectively altered by encounters with specific guidance features, the preaxonogenesis neurons.

\section{References}

Almers W, Neher E (1985) The calcium signal from fura-2 loaded mast cells depends strongly on the method of dye loading. FEBS Lett 192:13-18.

Anderson H (1988) Drosophila adhesion molecules and neural development. Trends Neurosci 11:472-475.

Anderson H, Tucker RP (1988) Pioneer neurones use basal lamina as a substratum for outgrowth in the embryonic grasshopper limb. Development 104:601-608.

Anglister L, Farber IC, Sharar CA, Grinvald A (1982) Location of voltage sensitive calcium channels along developing neurites: their possible role in regulation of neurite elongation. Dev Biol 94:351365 .

Bate CM (1976) Pioneer neurons in an insect embryo. Nature 260: 54-56.

Bennett MVL (1978) Junctional permeability. In: Intercellular junctions and synapses (Feldman J, Gilula NB, Pitts JD, eds), pp 25-36. London: Chapman and Hall.

Bentley D, Toroian-Raymond A (1986) Disoriented pathfinding by pioneer neurone growth cones deprived of filopodia by cytochalasin treatment. Nature 323:712-715.

Bixby JL (1989) Protein kinase C is involved in laminin stimulation of neurite outgrowth. Neuron 2:287-297.

Bolsover SR, Spector I (1986) Measurements of calcium transients in the soma, neurite and growth cone of single cultured neurons. J Neurosci 6:1934-1940.

Brehm P, Lechleiter J, Smith S, Dunlap K (1989) Intracellular signaling as visualized by endogenous calcium-dependent bioluminescence. Neuron 3:191-198.

Byerly L, Leung H-T (1988) Ionic currents of Drosophila neurons in embryonic cultures. J Neurosci 8:4379-4393. 
Caudy M, Bentley D (1986) Pioneer growth cone steering along a series of neuronal and non-neuronal cues of different affinities. J Neurosci 6:1781-1795.

Cohan CS, Kater SB (1986) Suppression of neurite elongation and growth cone motility by electrical activity. Science 232:1638-1640.

Cohan CS, Connor JA, Kater SB (1987) Electrically and chemically mediated increases in intracellular calcium in neuronal growth cones. J Neurosci 7:3588-3599.

Condic ML, Bentley D (1989a) Removal of the basal lamina in vivo reveals growth cone-basal lamina adhesive interactions and axonal tension in grasshopper embryos. J Neurosci 9:2687-2696.

Condic ML, Bentley D (1989b) Pioneer growth cone adhesion in vivo to boundary cells and neurons after enzymatic removal of basal lamina in grasshopper embryos. J Neurosci 9:2678-2686.

Condic ML, Bentley D (1989c) Pioneer neuron pathfinding from normal and ectopic locations in vivo after removal of the basal lamina. Neuron 3:427-439.

Connor JA (1986) Digital imaging of free calcium changes and spatial gradients in growing processes of single mammalian central nervous system cells. Proc Natl Acad Sci USA 83:6179-6183.

Connor JA, Tseng H-Y, Hockberger PE (1987) Depolarization- and transmitter-induced changes in intracellular $\mathrm{Ca}^{2+}$ of rat cerebellar granule cells in explant cultures. J Neurosci 7:1384-1400.

Dunlap K, Takeda K, Brehm P (1987) Activation of a calcium-dependent photoprotein by chemical signalling through gap junctions. Nature 325:60-62.

Fessler JH, Fessler LI (1989) Drosophila extracellular matrix. Annu Rev Cell Biol 5:309-339.

Forscher P (1989) Calcium and polyphosphoinositide control of cytoskeletal dynamics. Trends Neurosci 12:468-473.

Goldberg DG (1988) Local control of $\mathrm{Ca}^{2+}$ in formation of veils in growth cones. J Neurosci 8:2596-2605.

Grynkiewicz G, Poenie M, Tsien RY (1985) A new generation of $\mathrm{Ca}^{2+}$ indicators with greatly improved fluorescence properties. J Biol Chem $260: 3440-3450$.

Guthrie FB, Kater SB, Bentley D (1989) Guidepost cells act as calcium sinks for pioneer growth cones in vivo. Soc Neurosci Abstr 15:1261.

Haydon PG, McCobb DP, Kater SB (1984) Serotonin selectively inhibits growth cone motility and synaptogenesis of specific identified neurons. Science 226:561-564.

Ho RK, Goodman CS (1982) Pcriphcral pathways arc pioncercd by an array of central and peripheral neurones in grasshopper embryos. Nature 297:404-406.

Jan LY, Jan YN (1982) Antibodies to horseradish peroxidase as specific neuronal markers in Drosophila and grasshopper embryos. Proc Natl Acad Sci USA 79:2700-2704.

Kater SB, Mattson MP, Cohan C, Connor J (1988) Calcium regulation of the neuronal growth cone. Trends Neurosci 11:315-321.

Keshishian H (1980) The origin and morphogenesis of pioneer neurons in the grasshopper metathoracic leg. Dev Biol 80:388-397.

Keshishian H, Bentley D (1983) Embryogenesis of peripheral nerve pathways in grasshopper legs. 3. Development without pioneers. Dev Biol 96:116-124.

Klose M, Bentley D (1989) Transient pioneer neurons are essential for formation of an cmbryonic peripheral nerve. Science 245:982984.

Lankford KL, Letourneau PC (1989) Evidence that calcium may control neurite outgrowth by regulating the stability of actin filaments. $J$ Cell Biol 109:1229-1243.

Lefcort F, Bentley D (1987) Pathfinding by pioneer neurons in isolated, opened and mesoderm-free limb buds of embryonic grasshoppers. Dev Biol 1 19:466-480.

Lefcort F, Bentley D (1989) Organization of cytoskeletal elements and organelles preceding growth cone emergence from an identified neuron in situ. J Cell Biol 108:1737-1749.

Leung H-T, Branton WD, Phillips HS, Jan L, Byerly L (1989) Spider toxins selectively block calcium currents in Drosophila. Neuron 3: 767-772.
Lipscombe D, Madison DV, Poenie M, Reuter H, Tsien RY, Tsien RW (1988) Spatial distribution of calcium channels and cytosolic calcium transients in growth cones and cell bodies of sympathetic neurons. Proc Natl Acad Sci USA 85:2398-2402.

Mattson MP, Kater SB (1987) Calcium regulation of neurite elongation and growth cone motility. J Neurosci 8:4034-4043.

Mattson MP, Lee RE, Adams ME, Guthrie PB, Kater SB (1988) Interactions between entorhinal axons and target hippocampal neurons: a role for glutamate in the development of hippocampal circuitry. Neuron 1:865-876.

McCobb DP, Kater SB (1988) Membrane voltage and neurotransmitter regulation of neuronal growth cone motility. Dev Biol 130: 599-609.

McCobb DP, Cohan CS, Connor JA, Kater SB (1988) Interactive effects of serotonin and acetylcholine on neurite elongation. Neuron $1: 377-385$.

Morris CE, Sigurdson WJ (1989) Stretch-inactivated ion channels coexist with stretch-activated ion channels. Science 243:807-808.

Myers C, Whitington PM, Ball EE (1990) Embryonic development of the innervation of the locust extensor tibiae muscle by identified neurons: formation and elimination of inappropriate axon branches. Dev Biol 137:194-206.

O'Connor TP, Duerr JS, Bentley D (1990) Pioneer growth cone steering decisions mediated by single filopodial contacts in situ. J Neurosci 10:3935-3946.

Pauron D, Qar J, Barhanin J, Fournier D, Cuany A, Pralavorio M, Berge JB, Lazdunski M (1987) Identification and affinity labeling of very high affinity binding sites for the phenylalkylamine series of $\mathrm{Ca}^{++}$ channel blockers in the Drosophila nervous system. Biochemistry 26 : 6311-6315.

Ryerse JS (1989) Isolation and characterization of gap junctions from Drosophila melanogaster. Cell Tissue Res 256:7-16.

Saez JC, Connor JA, Spray DC, Bennett MV (1989) Hepatocyte gap junctions are permeable to the second messenger, inositol 1,4,5-triphosphate, and to calcium ions. Proc Natl Acad Sci USA 86:27082712.

Schuch U, Lohse MJ, Schachner M (1989) Neural cell adhesion molecules influence second messenger systems. Neuron 3:13-20.

Sigurdson WJ, Morris CE (1989) Stretch-activated ion channels in growth cones of snail neurons. J Neurosci 9:2801-2808.

Silver RA, Lamb AG, Bolsover SR (1989) Elevated cytosolic calcium in the growth cone inhibits neurite elongation in neuroblastoma cells: correlation of behavioral states with cytosolic calcium concentration. J Neurosci 9:4007-4020.

Silver RA, Lamb AG, Bolsover SR (1990) Calcium hotspots caused by $L$-channel clustering promote morphological changes in neuronal growth cones. Nature 343:751-754.

Snow PM, Patel NH, Harrelson AL, Goodman CS (1987) Neuralspecific carbohydrate moiety shared by many glycoproteins in Drosophila and grasshopper embryos. J Neurosci 7:4137-4144.

Spray DC, Bennett MVL (1985) Physiology and pharmacology of gap junctions. Annu Rev Physiol 47:281-303.

Streit J, Lux HD (1989) Distribution of calcium currents in sprouting PC12 cells. J Neurosci 9:4190-4199.

Sun YA, Poo MM (1987) Evoked release of acetylcholine from the growing embryonic neuron. Proc Natl Acad Sci USA 84:2540-2544.

Taghert PH, Bastiani MJ, Ho RK, Goodman CS (1982) Guidance of pioneer growth cones: filopodial contacts and coupling revealed with an antibody to Lucifer yellow. Dev Biol 94:391-399.

Tolkovsky AM, Walker AE, Murrell RD, Suidan HS (1990) $\mathrm{Ca}^{2+}$ transients are not required as signals for long-term neurite outgrowth from cultured sympathetic neurons. J Cell Biol 110:1295-1306.

Wei A, Salkoff L (1986) Occult Drosophila calcium channels and twinning of calcium and voltage-activated potassium channels. Science 233:780-782. 